\title{
Maillard Reaction of Pidan White as Inhibited by Chinese Black Tea Extract (Camellia sinensis) in the Pickling Solution
}

\author{
Palanivel Ganesan ${ }^{1,2, *}$, Soottawat Benjakul', and Badlishah Sham Baharin ${ }^{1}$ \\ ${ }^{1}$ Department of Food Technology, Universiti Putra Malaysia, Serdang 43400, Selangor, Malaysia \\ ${ }^{2}$ Department of Food Technology, Faculty of Agro-Industry Prince of Songkla University, \\ Hat Yai, Songkhla, Thailand, 90112
}

\begin{abstract}
Changes in Maillard reaction of pidan white were monitored with $\mathrm{A}_{294}$ fluorescence intensity, and browning intensity during pickling in the absence and presence of Chinese black tea extract (Camellia sinensis) at levels of 2\% and 5\% together with $0.2 \% \mathrm{ZnCl}_{2}$ or $0.2 \% \mathrm{CaCl}_{2}$ up to $3 \mathrm{wk}$, followed by ageing for another $3 \mathrm{wk}$. Browning intensity and $\mathrm{A}_{294}$ of pidan white increased with increasing pickling/ageing, while fluorescence intensity decreased during ageing $(p<0.05)$, irrespective of treatments. At wk 6, pidan white treated with $0.2 \% \mathrm{ZnCl}_{2}$ and $0.2 \% \mathrm{CaCl}_{2}$ showed slightly higher browning intensity, fluorescence intensity and $\mathrm{A}_{294}$ than those treated with divalents together with Chinese black tea $(p<0.05)$. Free amino group and sugar contents showed continuous decrease during pickling and ageing irrespective of tea and cations used. However, pidan treated without Chinese black tea extract showed significantly lower free amino group and sugar during the ageing of $6 \mathrm{wk}$ $(p<0.05)$. Thus, Chinese black tea extract had an inhibitory effect on the Maillard reaction during ageing of pidan white.
\end{abstract}

Keywords: pidan, Maillard, fluoresence intensity, browning, tea

\section{Introduction}

Duck egg products are very few in the market, among them pidan plays a very important diet role in many south east Asian countries and China (Ganesan and Benjakul, 2010, 2011; Su and Lin, 1994). Pidan is normally made by pickling the eggs in $4.2 \% \mathrm{NaOH} / 5.0 \% \mathrm{NaCl}$ solution at room temperature $\left(30^{\circ} \mathrm{C}\right)$ for $20 \mathrm{~d}(\mathrm{Su}$ and $\mathrm{Lin}, 1994)$. The formation of pidan is caused by the penetration of alkali through the egg shell and membrane, leading to chemical changes in the egg components (Ganasen et al., 2013). This results in gelation of the albumen during pickling at the alkaline condition. $\mathrm{Zn}^{2+}$ is used to produce pidan with no black spots on the egg shell, and the color of the pidan's albumen and yolk was more stable (Chen and Su, 2004; Ganesan and Benjakul, 2011).

Generally people believed that the use of Chinese black tea extract in pickling solution add a more detectable color and a characteristic flavor to pidan. Li et al. (2004)

\footnotetext{
*Corresponding author: Palanivel Ganesan, Department of Food Technology, Universiti Putra Malaysia, Serdang 43400, Selangor, Malaysia, Tel: +60-3-8946-8495, Fax: +60-3-8942-3552, E-mail: palanive167@gmail.com
}

reported that the color may be due to the Malliard reactions between the glucose and amino acid. Non-enzymatic interaction between a reducing sugar and an amino acid, peptide or protein has been known as the Maillard reaction. Glycosylation or glycation is an important reaction, which induces the covalent attachment of sugars to a- or e- $\mathrm{NH}_{2}$ groups of amino acids and protein to form glycated proteins (Friedman, 1996). The Maillard reaction produces a variety of intermediate products and finally brown pigments (melanoidins) are formed. The Maillard reaction is influenced by many factors, including reactant concentration, temperature, time, initial $\mathrm{pH}$ and water activity (Baxter, 1995; Naranjo et al., 1998; Wijewickreme et al., 1997).

In general, pidan white characteristic including good texture with amber/brown color is a quality index for consumers. However, no information regarding the changes of Maillard reaction of pidan white during pickling and ageing process, particularly those pickled in the presence or absence of Chinese black tea extract and alternative divalent, has been reported. Therefore, the objectives of this study were to investigate the changes in physical properties of pidan white produced with and without Chinese black tea extract and alternative divalent during pickling 
and ageing for up to $6 \mathrm{wk}$.

\section{Materials and Methods}

\section{Chemicals}

Zinc chloride $\left(\mathrm{ZnCl}_{2}\right)$, calcium chloride $\left(\mathrm{CaCl}_{2}\right)$, sodium hydroxide and sodium chloride were purchased from LabScan (Bangkok, Thailand). 2,4,6-Trinitrobenzenesulfonic acid (TNBS) and L-leucine, were purchased from SigmaAldrich, USA. Glucose and other chemicals were purchased from Merck, Germany.

\section{Duck egg collection}

Fresh eggs of duck (Anas platyrhucus) with the weight range of 65-75 $\mathrm{g}$ were obtained within $1 \mathrm{~d}$ of laying from a farm in Rathabhum, Songhkla Province, Thailand. Duck eggs were cleaned and checked for any crack prior to pickling.

\section{Preparation of pidan}

Clean duck eggs were soaked in a pickling solution containing $4.2 \% \mathrm{NaOH}, 5 \% \mathrm{NaCl}$ and $0.2 \% \mathrm{ZnCl}_{2}$ or $\mathrm{CaCl}_{2}$. Chinese black tea (Camellia sinensis) powder extract was added in the pickling solution at the concentrations of $2 \%$ and $5 \%$. Without Chinese black tea extract of both cations were taken as control. Sixty eggs were soaked in different pickling solutions $(6 \mathrm{~L})$ at room temperature $\left(30-32^{\circ} \mathrm{C}\right)$ for 3 wk. Pickled eggs were removed and coated with white clay paste (clay: water, $4: 1 \mathrm{w} / \mathrm{v}$ ) to obtain a thickness of 2-3 mm. Coated eggs were left at room temperature for another three weeks for ageing. During pickling and ageing, the samples were taken for analyses every week.

\section{Measurement of UV-absorbance}

The UV-absorbance of pidan white samples with 20 fold dilution were measured according to the method of Ajandouz et al. (2001). Appropriate dilution (20-fold) was made using distilled water and the absorbance was measured at 294 using a UV-1601 spectrophotometer (Shimadzu, Japan) for UV-absorbance.

\section{Measurement of fluorescence}

Fluorescence of pidan white samples with 20-fold dilution was determined as described by Morales and Jimenez-Perez (2001). The fluorescence intensity was measured at an excitation wavelength of $347 \mathrm{~nm}$ and an emission wavelength of $415 \mathrm{~nm}$ using a RF-1501 Fluores- cence spectrophotometer (Shimadzu, Japan).

\section{Measurement of browning intensity}

Browning intensity of pidan white samples of all treatments was determined as described by Benjakul et al. (2005). Appropriate dilution (20-fold) was made using distilled water and the absorbance was measured at 420 nm using a UV-160 spectrophotometer (Shimadzu, Japan).

\section{Determination of free amino group content}

Free amino group content was determined according to the method of Benjakul and Morrissey (1997). Pidan white samples (100-fold dilution) $(125 \mu \mathrm{L})$ were mixed with $2.0 \mathrm{~mL}$ of $0.21 \mathrm{M}$ phosphate buffer, $\mathrm{pH} 8.2$, and $1.0 \mathrm{~mL}$ of $0.01 \%$ TNBS solution was then added. The solutions were mixed thoroughly and placed in a temperature-controlled water bath (Memmert, Germany) at $50^{\circ} \mathrm{C}$ for 30 min in the dark. The reaction was terminated by adding $2.0 \mathrm{~mL}$ of $0.1 \mathrm{M}$ sodium sulfite. The mixtures were cooled at room temperature for $15 \mathrm{~min}$. The blank was prepared in the same manner as the samples except that distilled water was used instead of $0.01 \%$ TNBS. The absorbance was measured at $420 \mathrm{~nm}$. Free amino group content was expressed in terms of 1-leucine.

\section{Determination of reducing sugar content}

Reducing sugar content was determined according to the method of Chaplin (1994). All reagents were prepared as described by Chaplin (1994). One $\mathrm{mL}$ of pidan white samples (100-fold dilution) was mixed with $1.0 \mathrm{~mL}$ of reagent $\mathrm{C}$ in screw-sealed tubes. The mixtures were heated in a boiling water for $15 \mathrm{~min}$ and then cooled with tap water. One $\mathrm{mL}$ of reagent $\mathrm{D}$ was added and mixed well. Finally, $3 \mathrm{~mL}$ of deionised water was added to the mixtures. The absorbance was measured at $520 \mathrm{~nm}$. The reducing sugar content was calculated from the standard curve.

\section{Statistical analysis}

Completely randomized design was used throughout the study. The experiments were run in triplicate. Data were presented as mean values with standard deviations. Oneway analysis of variance (ANOVA) was carried out and means comparisons were run by Duncan's multiple range tests (Steel and Torrie, 1980). Statistical analyses were performed with the statistical program (SPSS for windows (Version 10), SPSS Inc, USA). 


\section{Results and Discussion}

\section{Changes in $A_{294}$, fluorescence intensity and $A_{420}$ of pidan white}

Continuous increases in $\mathrm{A}_{294}$ of pidan white samples were observed during pickling and ageing, irrespective of treatments (Fig. 1A). Pidan white treated with $0.2 \% \mathrm{ZnCl}_{2}$ or $0.2 \% \mathrm{CaCl}_{2}$ (without Chinese black tea extract) showed the higher increase in $\mathrm{A}_{294}$ values followed by Chinese black tea extract irrespective of cations used $(p<0.05)$. Absorbance at $294 \mathrm{~nm}$ was used to determine the intermediate compounds of the Maillard reaction (Ajandouz et al., 2001; Lerici et al., 1990). From the result, the increase in absorbance at $294 \mathrm{~nm}$ suggested the formation of an uncolored compound, which could be the precursor of the Maillard reaction (Ajandouz et al., 2001). This was more likely due to the higher formation of intermediate generated during a very high alkaline $\mathrm{pH}$. However the treatment with Chinese black tea extract irrespective of cations prevents the formation of colorless intermediate to some extent leads to lower absorbance. Different intermediate products are formed, either fluorescent or non-fluorescent compounds, during the Maillard reaction (Benjakul et al., 2005). From the result, it appears that some intermediate products might undergo conversion to the final brown compounds, while some intermediates are still being generated.

Fluorescence intensity of all pidan white samples increased gradually during pickling (Fig. 1B). Subsequently, a gradual decrease was observed up during ageing, irrespective of treatments $(p<0.05)$. Generally, increase in $\mathrm{pH}$ of the system influenced the Maillard reaction rate (Martins et al., 2003). The Maillard reaction is associated with the development of fluorescent compounds formed prior to the generation of brown pigments (Baiser and Labuza, 1992; Morales et al., 1996). This fluorescent compounds may be precursors of brown pigments (Morales and Van Boekel, 1997). The lower fluorescence intensity of pidan white during ageing was probably caused by the rapid transformation of the intermediates to brown compounds. This led to less remaining fluorescent intermediate products, as shown by the lowest fluorescence intensity. However, the pidan white treated with $0.2 \% \mathrm{ZnCl}_{2}$ or $0.2 \%$ $\mathrm{CaCl}_{2}$ (without Chinese black tea extract) showed significantly higher confirmed that fluorescent compounds also formed during ageing process $(p<0.05)$. Thus, those intermediate products might be different in terms of generation and reactivity of to form brown pigment. From the result, it was postulated that fluorescent compounds

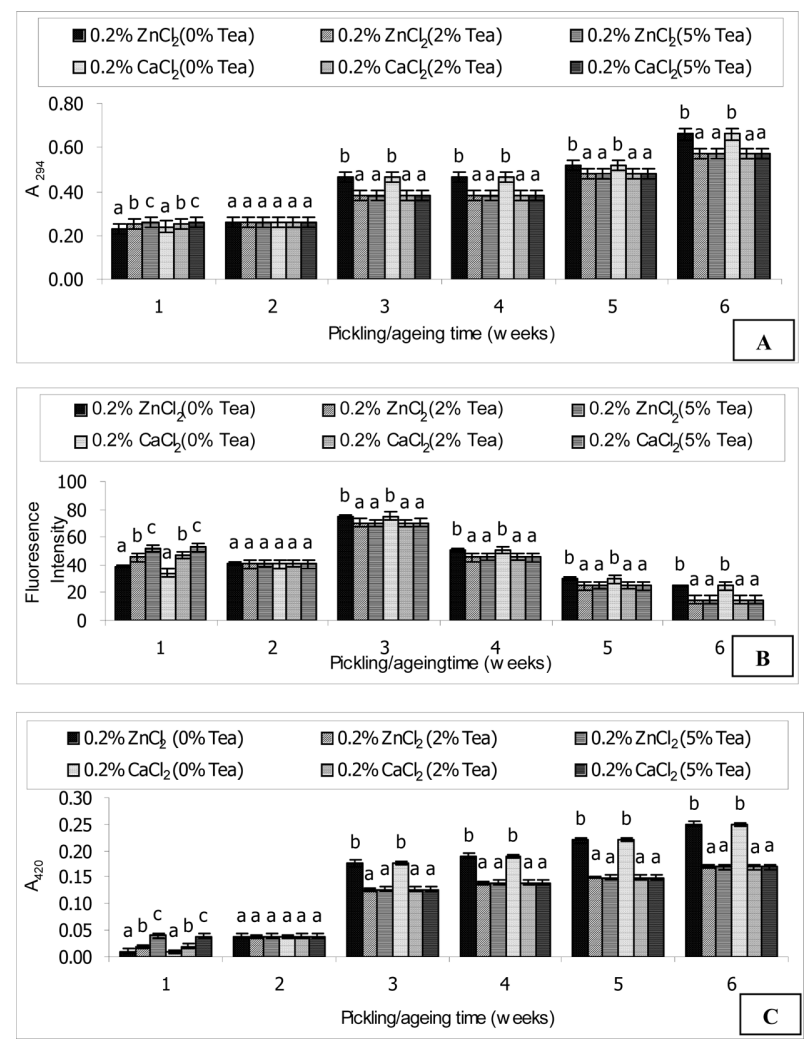

Fig. 1. Changes in $A_{294}$ (A), fluorescence intensity (B) and browning intensity (C) of pidan white pickled without and with addition of Chinese black tea extract at various levels along with different divalent cations. Bars indicate the SD from triplicate determinations.

might undergo the polymerisation to form brown pigment much faster than those with the UV absorbing property during ageing.

Continuous increases in $\mathrm{A}_{420}$ of pidan white samples were observed during pickling and ageing, irrespective of treatments (Fig. 1C). Maillard reaction is a non-enzymatic browning reaction which links the carbonyl group of reducing carbohydrates and the amino group of free amino acids as well as of lysine residues in proteins (Ajandouz et al., 2001). Maillard reaction is considered important in pidan white because of the significant amount of glucose naturally present in the egg white proteins. The browning intensity increased with increasing pickling and ageing times, irrespective of the treatments. At wk 1, pidan white treated with $0.2 \% \mathrm{ZnCl}_{2}$ or $0.2 \%$ $\mathrm{CaCl}_{2}$ along with Chinese black tea extract at various levels showed increase in browning intensity of pidan white most likely due to the staining effect of Chinese black tea extract used in the pickling solution. Furthermore, tea in pickling solution might enhance the brown color in the pidan white gels due to oxidation of flavonols in the alka- 
line environment. Mizooku et al. (2001) reported that the oxidation of flavanols was determined by $\mathrm{pH}$. Flavanols was colorless in aqueous solution at $\mathrm{pH}$ 7.6; however it turned yellow at $\mathrm{pH}$ 10.6. However as the pickling/ ageing time increased to wk 6 , pidan white treated with $0.2 \%$ $\mathrm{ZnCl}_{2}$ or $0.2 \% \mathrm{CaCl}_{2}$ along with Chinese black tea extract at various levels showed the lower browning intensity, compared with other treatments $(p<0.05)$. Similarly, Oral et al. (2014), also reported that addition of certain polyphenols inhibit Maillard reaction products. Higher browning intensity of $0.2 \% \mathrm{ZnCl}_{2}$ or $0.2 \% \mathrm{CaCl}_{2}$ (without cations) obtained with increasing pickling and ageing time was most likely due to the higher production and conversion of fluorescent compounds into brown pigment. This was in accordance with higher fluorescence intensity of pidan white.

\section{Changes in free amino group content and reducing sugar of pidan white}

Changes in free amino group and reducing sugar content of pidan white samples of various treatments are shown in Figs. 2A and 2B respectively. Continuous decrease in amino group and reducing sugar content of all pidan white samples was noticeable when the pickling and ageing time increased to wk $6(p<0.05)$. This result suggested that a $\alpha$ - or $\varepsilon-\mathrm{NH}_{2}$ group of amino acids or proteins which are hydrolyzed at very high alkaline $\mathrm{pH}$ covalently attached to a sugar to form glycated proteins to a greater extent, particularly when the pickling/ageing time increased to wk 6. The first glycation product, or Schiff base, rearranges to a more stable ketoamine or Amadori product. The Amadori products can then form cross-links between adjacent proteins or with other amino groups, resulting in polymeric aggregates called advanced glycation end-products (Friedman, 1996). From the results, the decreases in free amino group were in accordance with the increase in browning (Fig. 1C) and absorbance at 294 nm (Fig. 1A) and the decrease in fluorescence intensity (Fig. 1B). This indicated that increased pickling/ageing time catalysed the interaction between free amino groups, such as $\varepsilon-\mathrm{NH}_{2}$ groups of lysine, and sugar via glycation process. As a result, intermediate products were formed and further converted to brown pigments, as observed by the increased absorbance at $420 \mathrm{~nm}$. In general, pidan white treated without Chinese black tea extract was more reactive in forming the glycated product than with pidan white sample treated with Chinese black tea extract irrespective of cations, as shown by the greatest decrease in free amino groups and reducing sugar content with the

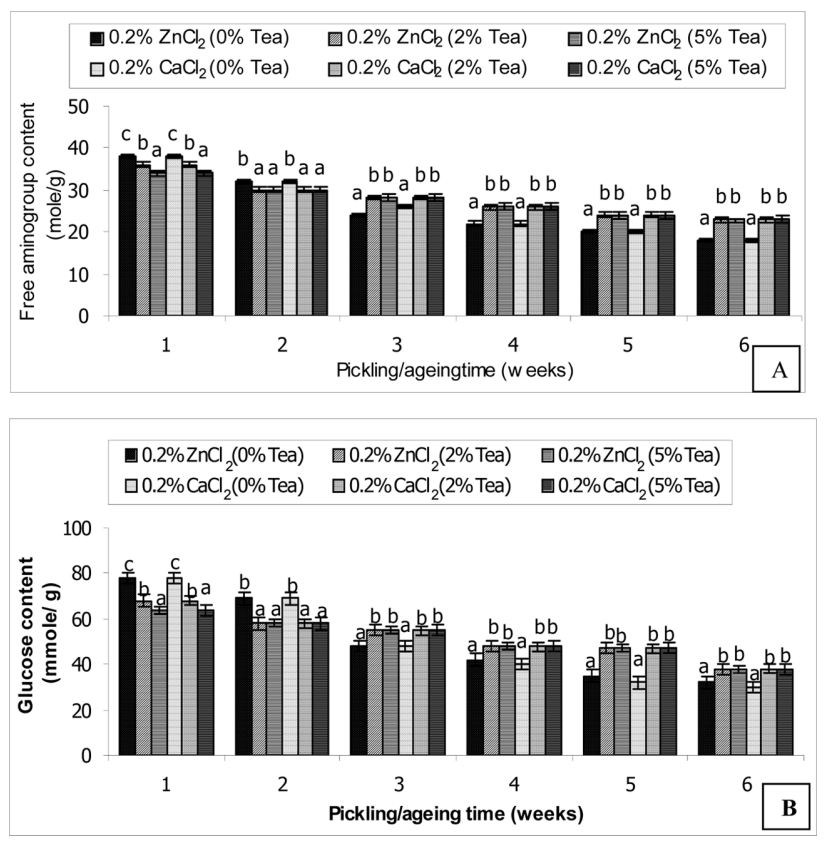

Fig. 2. Changes in free amino groups (A) and reducing sugar (B) of pidan white pickled without and with addition of Chinese black tea extract at various levels along with different divalent cations. Bars indicate the SD from triplicate determinations.

concomitant increase in browning. The reaction rate of glycation between casein and sugars depended on the percentage of the acyclic form and the electrophilicity of the carbonyl groups (Naranjo et al., 1998). The difference in reaction rate of sugar observed in many studies was possibly due to the conformation of protein.

In conclusion, Chinese black tea extract had inhibitory effect of developing brown colour during ageing of pidan white, where as it has staining effect during pickling. Fluorosence intensity follows the same trend as browning intensity of pidan white during pickling an ageing, irrespective of cations used. Therefore, brown color of pidan white was more likely mediated by Maillard reaction, not by Chinese black tea extract.

\section{Acknowledgements}

The authors would like to express their sincere thanks to Graduate School of Prince of Songkla University and Thai government for the financial support.

\section{References}

1. Ajandouz, E. H., Tchiapke, L. S., Ore, F. D., Benjibas, A., and Puigserver, A. (2001) Effect of $\mathrm{pH}$ on caramelisation and 
Maillard reaction kinetics in fructose-lysine model systems. J. Food Sci. 66, 926-932.

2. Baiser, W. M. and Labuza, T. P. (1992) Maillard browning kinetics in liquid model system. J. Agr. Food Chem. 40, 707713.

3. Baxter, J. H. (1995) Free amino acid stability in reducing sugar systems. J. Food Sci. 60, 405-407.

4. Benjakul, S. and Morrissey, M. T. (1997) Protein hydrolysates from Pacific whiting solid waste. J. Agr. Food Chem. 45, 3423-3430.

5. Benjakul, S., Lertittikul, W., and Bauer, F. (2005) Antioxidative activity of Maillard reaction products from a porcine plasma protein-sugar model system. Food Chem. 93, 189-196.

6. Chaplin, M. F. (1994) Monosaccharides. In: Carbohydrate Analysis: A practical approach. Chaplin, M. F. and Kennedy, J. F. (ed) IRL Press, Oxford. pp. 1-41.

7. Chen, J. W. and Su, H. P. (2004) A new process for preparing spots-free pidan. J. Chin. Soc. Anim. Sci. 33, 79-88.

8. Friedman, M. (1996) Food browning and its prevention: An overview. J. Agr. Food Chem. 44, 631-653.

9. Ganasen, P. and Benjakul, S. (2010) Physical properties and microstructure of pidan yolk as affected by different divalent and monovalent cations. LWT-Food Sci. Technol. 43, 77-85.

10. Ganasen, P. and Benjakul, S. (2011) Effect of three cations on the stability and microstructure of protein aggregate from duck egg white under alkaline condition. Food Sci. Technol. Int. 17, 343-349.

11. Ganasen, P., Benjakul, S., and Kishimura, H. (2013) Effect of different cations on pidan composition and flavor in comparison to the fresh duck egg. Korean J. Food Sci. An. 33, 214-220.

12. Lerici, C. R., Barbanti, D., Manzano, M., and Cherubin, S. (1990) Early indicators of chemical changes in foods due to enzymic or non enzymic browning reactions. 1: study on heat treated model system. LWT-Food Sci. Technol. 23, 289-294.
13. Li, J. R. and Hsieh, Y. H. (2004) Traditional Chinese food technology and cuisine. Asia Pac. J. Clin. Nutr. 13, 147-155.

14. Martins, S. I. F. S., Marcelis, A. T. M., and Van Boekel, M. A. J. S. (2003) Kinetic modeling of the Amadori $N$-(1-deoxy-dfructose-1-yl) glycine degradation pathway. Part I -reaction mechanism. Carbohydr. Res. 338, 1651-1663.

15. Mizooku, Y., Yoshikawa, M., Tsuneyoshi, T., and Arakawa, R. (2001) Analysis of oxidized epigallocatechin gallate by liquid chromatography/mass spectrometry. Rapid Commun. Mass Spectrom. 17, 1915-1918.

16. Morales, F. J. and Jimenez-Perez, S. (2001) Free radical scavenging capacity of Maillard reaction products as related to colour and fluorescence. Food Chem., 72, 119-125.

17. Morales, F. J. and Van Boekel, M. A. J. S. (1997) A study on advanced Maillard reaction in heated casein-sugar solution: fluorescence accumulation. Int. Dairy J. 7, 675-683.

18. Morales, F. J., Romero, C., and Jimenez-Perez, S. (1996) Fluorescence associated with Maillard reaction in milk and milkresembling system. Food Chem. 67, 423-428.

19. Naranjo, G. B., Malec, L. S., and Vigo, M. S. (1998) Reducing the sugar's effect on available lysine loss of casein by moderate heat treatment. Food Chem. 62, 309-313.

20. Oral, R. P., Dogan, M., and Sarioglu, K. (2014) Effects of certain polyphenols and extracts on furans and acrylamide formation in model system, and total furans during storage. Food Chem. 142, 423-429.

21. Steel, R. G. D. and Torrie, J. H. (1980) Principles and procedures of statistics McGraw-Hill Book New York, USA.

22. Su, H. and Lin, C. W. (1994) Effect of processing conditions of the formation of lysinoalanine in duck Pidan. J. Chin. Soc. Anim. Sci. 23, 323-330.

23. Wijewickreme, A. N. and Kitts, D. D. (1997) Influence of reactions on the oxidative behavior of model Maillard reaction products. J. Agr. Food Chem. 45, 4571-4576.

(Received 2013.9.23/Revised 2014.2.10/Accepted 2014.2.11) 